\title{
Concept of a System Using a Dynamic SWOT Analysis Network for Fuzzy Control of Risk in Complex Environments
}

\author{
Vytautas Petrauskas*, Raimundas Jasinevicius, Egidijus Kazanavicius, Zygimantas Meskauskas \\ Centre of Real Time Computer Systems, Kaunas University of Technology, Kaunas, Lithuania \\ Email address: \\ vytautas.petrauskas@ktu.lt (V. Petrauskas), raimundas.jasinevicius@ktu.lt (R. Jasinevicius), egidijus.kazanavicius@ktu.lt (E. Kazanavicius), \\ zygmes@gmail.com (Z. Meskauskas) \\ ${ }^{*}$ Corresponding author
}

\section{To cite this article:}

Vytautas Petrauskas, Raimundas Jasinevicius, Egidijus Kazanavicius, Zygimantas Meskauskas. Concept of a System Using a Dynamic SWOT Analysis Network for Fuzzy Control of Risk in Complex Environments. Mathematics and Computer Science. Vol. 5, No. 2, 2020 , pp. $42-55$. doi: $10.11648 /$ j.mcs.20200502.11

Received: March 13, 2020; Accepted: March 30, 2020; Published: April 7, 2020

\begin{abstract}
The paper advocates a new concept for risk control that makes up one organic closed loop feedback system, with the following stages: 1) the evaluation of the positive and negative features of situation under investigation through strengths, weaknesses, opportunities, and threats (SWOT) analysis, 2) the determination of the level of fuzzy risk concealed in this situation (using RISK evaluation), and 3) the proposal of leverage, recommendations, or actions (through LEVERAGE aggregation) enabling the improvement of target performance. Useful fundamental approaches, definitions, and particularities of this concept concerning SWOT, RISK and LEVERAGES are examined, and for the first time the network type called here the fuzzy SWOT map (FSM) is introduced. This newly proposed instrument appeared as a result of a natural extension of fuzzy cognitive maps paradigm enhanced by dynamic computing with words (CWW) elements and possibilities to use the explainable artificial intelligence (XAI) in the form of fuzzy inference rules. The concept serves for development of functional organization of control systems of complex and dynamically interacting projects or situations and for implementation of adequate set of tools satisfying the concrete system's requirements. The results of conceptual modeling and the confirmation of the vitality of the approach are presented based on the simplified example of a risk-control system case covering three interacting projects in a complex environment of city development.
\end{abstract}

Keywords: Complex Systems Science, Dynamic SWOT Analysis, SWOT Engines Networking, Fuzzy SWOT Maps, CWW (Computing with Words), Risk Definition, Fuzzy Risk Evaluation Paradigm, Fuzzy Control System, Conceptual Modeling

\section{Introduction}

There are two main complementary scientific tendencies present in our everyday lives. The first one of these is globalization, which under the force of which each of us is coming to live in an evolving, overlapping, and interacting world and its socio-technical fabric. The other is each group's own growth, which results in the creation of new complex technologies and systems whose behavior is often unpredictable or even risky. For both, there is a lack of an adequate theoretical approach to the contemporary practical problems that arise [1-3]. However, it is evident that a survival, appropriate or even efficient activity, and comfort or good results can only be achieved or guaranteed when a complete analysis is performed, all possible risks are evaluated and taken into account, and all necessary actions are performed.

The most commonly and widely used means of evaluating ideas, plans, and activities are strengths, weaknesses, opportunities, and threats (SWOT) analysis. There is a large amount of literature devoted to SWOT analysis, even from its beginning somewhere from Harvard or Stanford schools times in the 1960s [4]. It is clear that this methodology played an important role in a variety of fields, including 
politics, military, economics, industry, health services, demographics, technology, and government.

Under the influence of contemporary dynamic and structural changes in the space and time dimensions of environments and processes under investigation, adequate (flexible, rapid, and hierarchically interconnected) SWOT analysis tools are required that are able to focus on more than one moment in time in the life of an organization or system. Another significant drawback in the classical methodology of SWOT analysis can be found in the form of the input information and its interpretation: expert teams usually use a mixture of quantitative (numerical) information and qualitative (verbal) description of situations under investigation as their inputs, and they extract and deliver qualitative interpretations in their recommendation for action to be taken to address a given situation.

This paper: 1) introduces and expands the dynamic approach to SWOT analysis as it was firstly proposed in [5] and [6], using the mechanism of dynamic fuzzy cognitive maps; 2) introduces the possibility of using quantitative and qualitative input and output data as well as to the verbal SWOT reasoning, using the paradigm of computing with words (CWW) as was firstly proposed for such procedure in [8]; 3) provides SWOT expert teams with the support tools for reasoning and decision making using fuzzy risk analysis, following the risk paradigm presented in [9], which methodologically corresponds to the conclusions provided in [7]. The definition, assessment, and management remains shaky and unfounded in general, so we selected and invented our own metrics for fuzzy risk with the aim of making them useful for decision makers in SWOT analysis. Here, the proposed definition of risk and the corresponding metrics, based on fuzzy reasoning procedures, allow us to construct leverage in the form of recommendations, signals, and/or actions to be inserted into the environment subjected to SWOT analysis and control that has optimization of the dynamic performance of the whole system as its goal.

Thus, a new concept of a closed-loop feedback system is presented here that improves the performance of processes in a certain environment under consideration; the quality of those processes is analyzed by the newly developed SWOT+CWW tools, and after the RISK evaluation the system proposes adequate LEVERAGE for use in control.

The paper is organized as follows. The necessary preliminaries are presented in Section 2. The functional organization of the system is indicated in Section 3. Sections 4 and 5 are devoted to describe the system's implementation and results of experimental modeling. Concluding remarks are delivered in Section 6.

\section{Preliminaries}

As stated in Introduction, this paper advocates a new concept that combines in one organic closed loop feedback system evaluation (through SWOT analysis) of the positive and negative features of a situation under investigation, the determination (through RISK evaluation) of the level of fuzzy risk concealed in this situation, and the proposal (through LEVERAGE aggregation) of leverage / recommendations / actions that would enable the improvement of the given situation's performance. Here, we present useful fundamental approaches, definitions, and particularities regarding our concept, in particular the items SWOT, RISK, and LEVERAGES.

First of all, it is considered that a given situation originates in some element $e_{e}$ of the environment (as indicated in Figure 1 ), characterized by the following vectors, indicating strengths, weaknesses, opportunities, and threats, respectively:.

$$
\left\{\begin{array}{l}
\overrightarrow{S T_{e}}=\left(S T_{e 1}, \ldots, S T_{e s}, \ldots, S T_{e S}\right), \quad \text { es }=(1, \ldots, e s, \ldots, e S) \\
\overrightarrow{W K_{e}}=\left(W K_{e 1}, \ldots, W K_{e w}, \ldots, W K_{e W}\right), \quad \text { ew }=(1, \ldots, e w, \ldots, e W) \\
\overrightarrow{O P_{e}}=\left(O P_{e 1}, \ldots, O P_{e o}, \ldots, O P_{e o}\right), \quad \text { eo }=(1, \ldots, e o, \ldots, e O) \\
\overrightarrow{T H_{e}}=\left(T H_{e 1}, \ldots, T H_{e t}, \ldots, T H_{e T}\right), \quad \text { et }=(1, \ldots, e t, \ldots, e T)
\end{array}\right.
$$

All elements of vectors presented are given in numerical form.

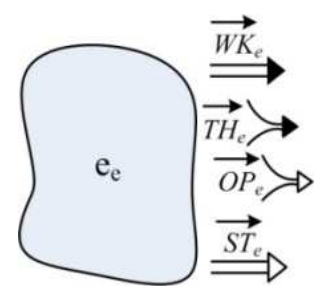

Figure 1. Element $e_{e}$ of the environment.

The evaluation of features of a situation is conducted using the well-known procedure SWOT analysis [8], incorporating a SWOT engine (Figure 2).

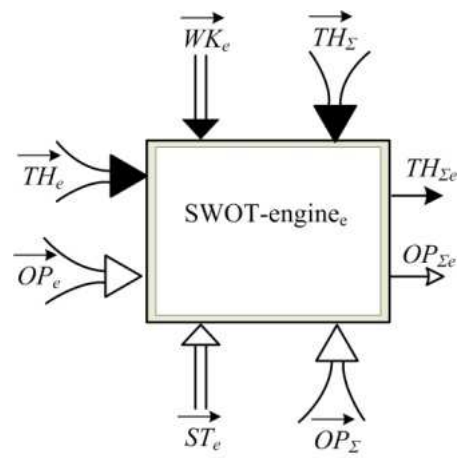

Figure 2. SWOT engine.

In the expressions

$$
\left\{\begin{array}{l}
O P_{\sum e}=\sum_{e o=1}^{e O}\left\{c_{e o}\left(\rho_{e o}+\sum_{e s=1}^{e S} S T_{e o s}+\sum_{e w=1}^{e W} W K_{o e w}\right)\right\}+O P \Sigma \\
T H_{\sum e}=\sum_{e t=1}^{e T}\left\{c_{e t}\left(\rho_{e t}+\sum_{e s=1}^{e S} S T_{e t s}+\sum_{e w=1}^{e W} W K_{e t w}\right)\right\}+T H \Sigma
\end{array}\right.
$$

$c_{e o}(o=1, \ldots, O)$ indicates the degree of importance for each possible or predicted opportunity, and $c_{e t}(t=1, \ldots, T)$ is the importance degree of each possible or predicted threat in the interval $[0-1]$ for this particular situation or project. The initial values of truth $\rho_{e o}, \rho_{e t}$ for all $o=1, \ldots, O$ and $t=1, \ldots$, $T$ in the same interval [0-1] are shown as well. $O P \Sigma$ and $T H \Sigma$ symbolize other possible opportunities and threats that can arise in different elements or parts $e=1, \ldots, e, \ldots, E$ of 
complex environments under consideration, and their meaning will be discussed in more detail later on in this paper.

The novelty of our case is its proposal that experts use words from the selected vocabulary for the verbal evaluation of all possible entities during SWOT analysis ([8]). As far as we know, no other study has included the possibility of a CWW paradigm for SWOT analysis.

It is worth of emphasizing here that all these components in Eq. (2) must be symbolically aggregated and/or summed, keeping in mind the corresponding truth values received from the fuzzy terms of their membership functions, as described and elaborated in [9]. During the summary process, SWOT experts must confront one of at least two cases: 1) when the degree of fuzzy membership is evaluated numerically (type 1 fuzzy relations) or 2) when the degree of fuzzy membership is evaluated verbally (type 2 fuzzy relations) ([14]).

Formally, we use vector-vocabulary, as follows:

$$
\{\vec{\alpha}\}=\left(\left\{\alpha_{1}\right\}, \cdots,\left\{\alpha_{a}\right\}, \cdots,\left\{\alpha_{A}\right\}\right)
$$

which practically consists of A words (each word in curly brackets) expressing the following meanings:

$$
\left\{\begin{array}{l}
\{Z\}-\text { None/Zero } \\
\{V S\}-\text { Very small } \\
\{S\}-\text { Small } \\
\{M\}-\text { Medium } \\
\{L\}-\text { Large } \\
\{V L\}-\text { Very large }
\end{array}\right.
$$

These serve to name fuzzy terms in membership functions, as shown in our previous work [8]. Terms corresponding to the ability of human beings to distinguish and evaluate not more than seven plus or minus two grades of qualitative difference are presented in Figure 3.

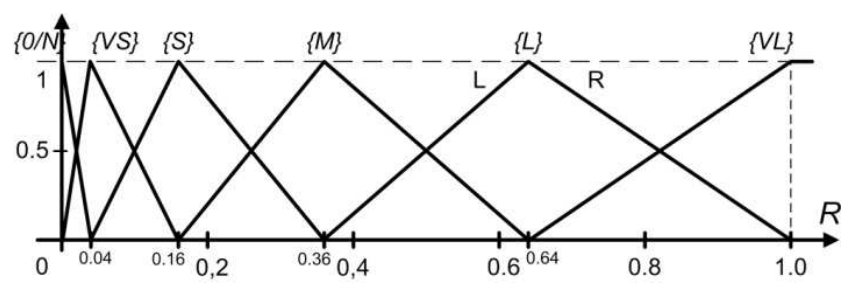

Figure 3. Membership functions for the words of the selected vocabulary.

The determination of the level of fuzzy risk concealed in a situation or project under consideration is based on our paradigmatic definition of risk presented in [9], and it constructively contradicts the opinion expressed in [10]. In this paper, risk is considered to be a normalized subjective level of the uncertainty of the consequences of activity and/or the state of the system of entities in complex environments. The results of SWOT analysis support the understanding or evaluation (numerical or verbal) of possible negative results $T H_{\Sigma e}$, such as losses, threats, or disappointments, or possible positive results $\left(O P_{\Sigma e}\right)$, such as achievements, or profits, opportunities, or joy. If activities (EFF) such as effort or investment that are part of this are included in the consideration, and the dimension of uncertainty (HES or PROB), whether hesitancy, randomness, possibility, or probability of certain events, are taken into account ([11, 12, $17,18]$ ), a measurable level of risk $\mathrm{R}$ can be calculated as a value for a certain function $\mathcal{R}$, depending on EFF, OP, TH, and HES in an intuitive manner, as shown in Eq. (5):

$$
\mathrm{R}=\mathcal{R}(\mathrm{EFF} \uparrow ; \mathrm{OP} \downarrow ; \mathrm{TH} \uparrow ; \mathrm{HES} \uparrow / \mathrm{PROB} \downarrow)
$$

The arrows $\uparrow$ and $\downarrow$ mean increase and decrease in R, respectively.

A generalized risk evaluation engine is schematically presented in Figure 4. The informal reasoning presented in Eq. (5) is constructed using fuzzy evaluation of the $T H_{\Sigma e}$, $O P_{\Sigma e} E F F_{e}$ and $P R O B_{e}$ prescribed by an $I F \ldots T H E N$ type list or fuzzy rules $\left(\mathrm{LoR}_{\mathrm{Rr}}\right)$ drafted by experts. The final output $R_{r}$ can be aggregated using different strategies, as delivered and thoroughly discussed in [13,14], and elsewhere. The center of gravity (CoG) method ([15]) is used throughout this paper for its simplicity and effectiveness.

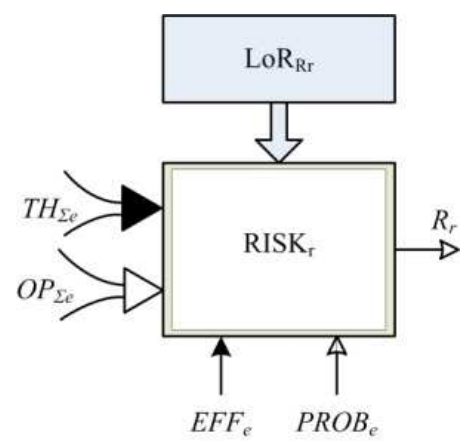

Figure 4. Generalized risk-evaluation engine.

A symbolic elaboration of the same risk-evaluation engine is given in Figure 5.

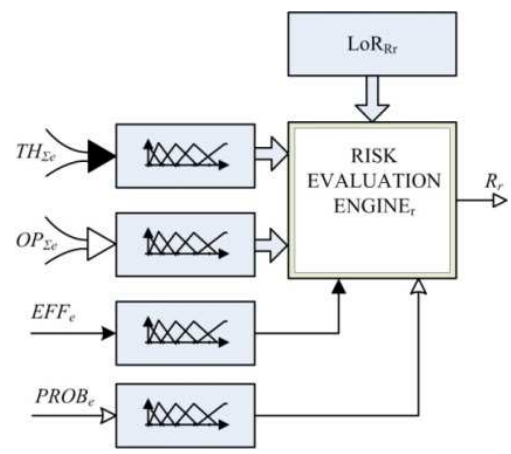

Figure 5. Detailed elaboration of the risk-evaluation engine.

The LEVERAGE aggregation stage system seeks proper leverage, recommendations, or even immediate actions to take that would enable improvement of the situation. The results of this aggregation are obtained using the risk evaluation, following similar fuzzy reasoning technology, which is symbolically presented in the Figure 6. This generalized structure of the AGGREG-engine permits to determine at least one item $L_{l}$ for leverage. 


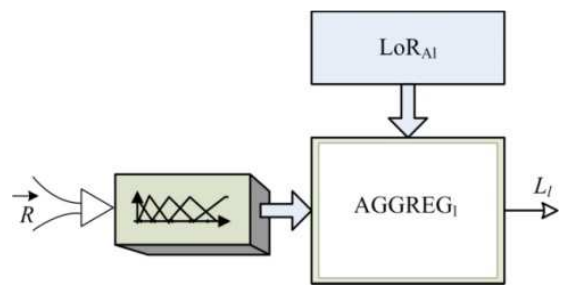

Figure 6. Generalized structure of engine for determination of leverage.

In this case, the combinations of the elements of the vector of different risks $\vec{R}=\left(R_{1}, \cdots, R_{e}, \cdots, R_{E}\right)$ obtained in the early stages of the risk determination are expertly evaluated verbally, using a list of the IF...THEN type fuzzy rules $\left(\operatorname{LoR}_{A 1}\right)$, and then the reasoning is summarized, also using the different strategies $([13,14])$; for this, the center of gravity $(\mathrm{CoG})$ methodology is generally preferred in our applications. Usually leverage item $L_{l}$ is used to close the loop of the feedback system and enable the improvement of performance in the situation or project under investigation.

The backbone of the concept being presented in this paper is the application of fuzzy control of risk in complex environments using a dynamic, network-based, closed-loop system using SWOT analysis that reflects the overlapping and interacting processes in the practical reality under investigation. This approach is supported by the opinion of Francisco Herrera et al. ([16]), who wrote, "In the future, more priority deriving methods will be done and we will adapt the IFANP to solve other MCDM problems, such as $R \& D$ project selection, strengths, weaknesses, opportunities, and threats (SWOT) analysis, logistics service provider selection, production planning and so forth."

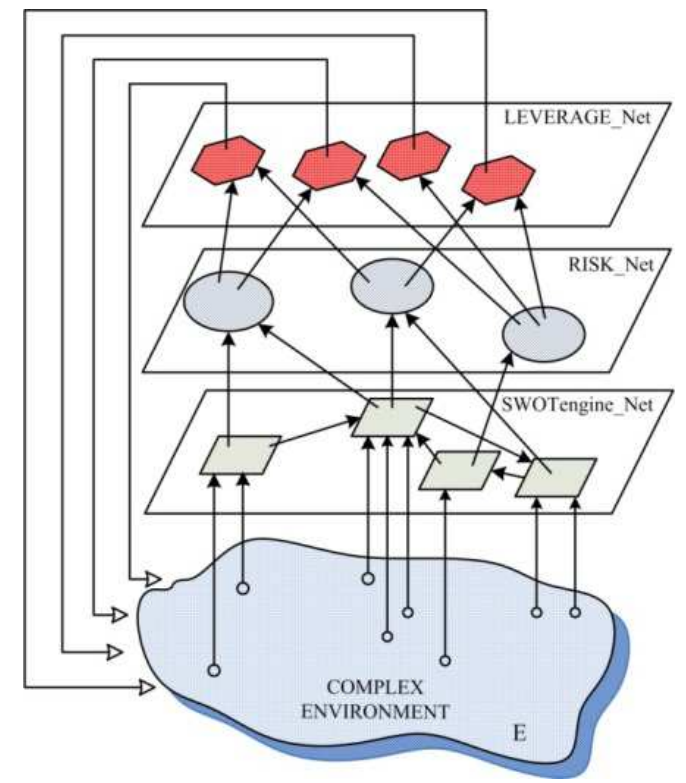

Figure 7. Hierarchical feedback system for fuzzy control of risk in complex environment.

Real situations, projects, phenomena, abstract ideas, and their overlapping and interacting combinations in a complex environment $(E)$ that is under investigation must be reflected by a corresponding dynamic SWOT analysis, as shown in
Figure 7, with reference to the SWOT engine_Net.

The closed-loop hierarchical-feedback system for fuzzy control of risk in a complex environment is shown in Figure 7 and can support more detailed explanation of the functional organization and implementation of the proposed concept.

\section{Functional Organization of the System}

The most important feature of a hierarchical feedback system for fuzzy control of risk in a complex environment (Figure 7) is the dynamic networking of interacting elements and entities, existing physically, geographically, or conceptually on various hierarchical levels throughout the activity of an entire system. As depicted in Figure 8, on each level, elements or entities are interacting, and the presentation of those interactions relates to real life experience and the consideration of experts. This describes interaction among the real parts of the environment $\left(e_{1}, \ldots\right.$, $\left.e_{e}, \ldots, e_{E}\right)$ and the corresponding SWOT engines, as well as about the risk that is to be taken into account, which relates to the knowledge, experience, and interests of experts. Likewise, potential leverages can also be constructed, proposed, and used, following similar principles.

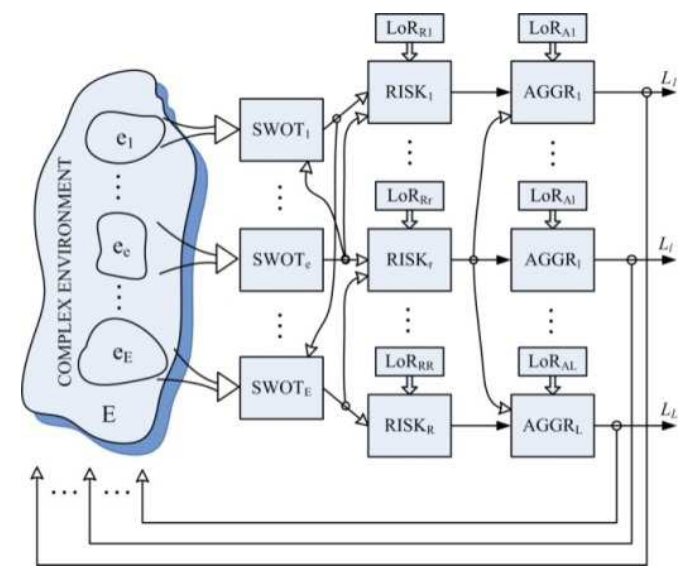

Figure 8. Presentation of interacting elements and entities.

Details and particular aspects of networking are discussed below.

\subsection{The SWOT Engine_Net Level}

The level of the SWOT engine _Net accounts for the fact that disadvantages can appear as threats $\left(T H_{\Sigma \mathrm{e}}\right)$ and, while they may be noticed in one particular part or subsystem of the complex environment, may cause additional threats, in other areas or to other entities they appear as potential positive actions (opportunities). Likewise, obtained or predicted advantages or possibilities $\left(O P_{\Sigma e}\right)$ must be evaluated as opportunities for some entities, and for - others they must be interpreted as disadvantages or threats.

It must be emphasized, that this networking of SWOT engines creates a complex dynamic closed loop system, even on the level of the SWOT engine_Net. This networked construct is similar to the well-known fuzzy cognitive map 
(FCM) idea that was presented and discussed by Bart Kosko in [13] and developed by many others elsewhere.

As has been noted ([21]), the functionality of FCM entities and edges are being extended step by step; this development process is portrayed in the Table 1 . This means that the networked SWOT engines must be considered additional and entirely novel versions of the more sophisticated FCM nodes. We call these fuzzy SWOT nodes, and the whole network of such nodes is called the fuzzy SWOT map (FSM).

Table 1. Process of extension of the FCM concept.

\begin{tabular}{|c|c|c|}
\hline Extension step & FCM characteristics & References \\
\hline 0 & Bivalent entities; trivalent edges (FCM) & {$[19,20,21]$} \\
\hline 1 & Nonlinear sensitivity of entities; linearly weighted edges (OFCM - as ordinary FCM) & [13] \\
\hline 2 & $\begin{array}{l}\text { Linear sensitivity with saturation of entities; nonlinear influence of each individually weighted edge (NFCM as } \\
\text { nonlinear FCM) }\end{array}$ & {$[25]$} \\
\hline 3 & Expert $I F \ldots T H E N$ type fuzzy knowledge inclusion in the OFCM case as linear fuzzy expert maps (FEM_L) & {$[26,21]$} \\
\hline 4 & Expert $I F \ldots T H E N$ type fuzzy knowledge inclusion in the NFCM case as nonlinear fuzzy expert maps (FEM_N) & {$[21,24]$} \\
\hline 5 & Inclusion of verbal SWOT analysis knowledge into the nodes of OFCM as fuzzy SWOT maps (FSMs) & [8], and this paper \\
\hline
\end{tabular}

Although in our case, the system is more complex, many properties of transient states, convergences, and stability of the system have the same character as for the appropriate
FCM. Using SWOT analysis formulae (2) and the FCM description mechanism from [8] and [14], the mathematical expression of SWOT-engines networking is given as follows:

$$
T H_{\Sigma e}[n]=\sum_{e t=1}^{e T}\left\{c_{e t}\left(\rho_{e t}+\sum_{e w=1}^{e W} W K_{e t w}[n-1]-\sum_{e s=1}^{e S} S T_{e t s}[n-1]\right)\right\}+\left\{\sum_{f=1}^{f=E}\left(V_{e f T} \times T H_{\Sigma f}[n-1]\right)+\sum_{f=1}^{f=E}\left(V_{e f O} \times O P_{\Sigma e}[n-1]\right)\right\}
$$

for $T H_{\Sigma \mathrm{e}}$ at the $n$-th step and

$$
O P_{\Sigma e}[n]=\sum_{e o=1}^{e O}\left\{c_{e o}\left(\rho_{e o}+\sum_{e s=1}^{e S} S T_{e o s}[n-1]-\sum_{e w=1}^{e W} W K_{e o w}[n-1]\right)\right\}+\left\{\sum_{f=1}^{f=E}\left(U_{e f o} \times O P_{\Sigma f}[n-1]\right)+\sum_{f=1}^{f=E}\left(U_{e f T} \times T H_{\Sigma e}[n-1]\right)\right\}
$$

for $O P_{\Sigma e}$ at the $n$-th step.

Here $f=(1, \cdots, e, \cdots, E)$ are the indexes of the SWOT engines to be networked.

$V_{e f T}=[+1,0,-1]$ is an auxiliary flag that only influences the threats $\overrightarrow{T H}_{\Sigma}$ of the SWOT engine $e$ and equals 0 if there is no edge from output $T H_{\Sigma f}$ of SWOT engine's $f$ to entrance $\overrightarrow{T H}$ of the SWOT engine $e$ (no edge exists from $f$ to $e$ ) but equals +1 , or -1 if an edge exists from output $T H_{\Sigma f}$ of the SWOT engine $f$ to the entrance $\overrightarrow{T H}$ of the SWOT engine $e$ and correspondingly increases or decreases its influence.

$U_{\text {efo }}=[+1,0,-1]$ is an auxiliary flag that only influences the opportunity $\overrightarrow{O P}_{\Sigma}$ of the SWOT engine $e$ and equals 0 if there is no edge from output $O P_{\Sigma f}$ of SWOT engine's $f$ to entrance $\overrightarrow{O P}$ of SWOT engine $e$ (no edge from $f$ to $e$ exists), but equals +1 , or -1 if an edge exists from output $O P_{\Sigma f}$ of the SWOT engine $f$ to the entrance $\overrightarrow{O P}$ of the SWOT engine $e$ and correspondingly increases or decreases its influence.

$n=1,2, \ldots, n, \ldots, N$ is the number of steps that describe the dynamics of processes for the SWOT engine _Net level on the FSM. The evident fact that these processes correspond to events in or the life of the complex environment under investigation is worth mentioning.

Results (6) and (7) $\left(\mathrm{TH}_{\Sigma e}, O P_{\Sigma e}\right)$ are comparable and can develop further consideration, but only after their normalization. It is obvious that this normalization can be achieved by involving coefficients of normalization (8) and (9) for threats and opportunities correspondingly:

$$
k_{T H e}=\frac{1}{e T(1+e W)+\sum_{f=1}^{f=E} \text { positive }\left(V_{e f T}\right)+\sum_{f=1}^{f=E} \text { positive }\left(V_{\text {efo }}\right)}
$$

and

$$
k_{O P e}=\frac{1}{e O(1+e S)+\sum_{f=1}^{f=E} \text { positive }\left(U_{e f O}\right)+\sum_{f=1}^{f=E} \text { positive }\left(U_{e f T}\right)}
$$

The remark positive means that only positive auxiliary flags are taken into account in all those sums as potentially capable to create maximal value of threats and possibilities according to (6) and (7). The coefficients for the normalization of (8) and (9) are determined after the analysis of (6) and (7), keeping in mind the fact that the maximal value of the summarized and normalized threat and of the summarized and normalized opportunity must not exceed 1 .

The summarized and normalized threat in the environment under consideration is as follows:

$$
T H_{\Sigma e}^{\text {norm }}=T H_{\Sigma e} \times k_{T H e}
$$

Likewise, the summarized and normalized opportunity for the same situation in the environment under consideration is as follows:

$$
O P_{\Sigma e}^{n o r m}=O P_{\Sigma e} \times k_{O P e}
$$

To maintain the simplicity of formal description and notation, the upper index (superscript) norm will be omitted in the following sections of this paper. This is considered unlikely to risk harming the understanding of the topics discussed.

\subsection{The RISK_Net Level}

Networking on the RISK_Net level collects threats and opportunities $\left(T H_{\Sigma \mathrm{e}}, O P_{\Sigma \mathrm{e}}\right)$ from all $\mathrm{SWOT}_{e}$ analyzers $(e=1$, $2, \ldots, e, \ldots, E)$ that are networked in the FSM and expertly predicts, constructs, and evaluates the possible and/or hypothetical risks $R_{r}(r=1,2, \ldots, r, \ldots, R)$. In the simplest case, $R=E$; however, in general, $R \neq E$. Each network component 
of the RISK Net level RISK r has the same structure, as indicated in Figures 4 and 5 , but the procedures used in this networking enable us to use $\overrightarrow{T H}_{\Sigma}=\left(T H_{\Sigma 1}, \cdots, T H_{\Sigma e}, \cdots, T H_{\Sigma E}\right)$ and $\overrightarrow{O P}_{\Sigma}=\left(O P_{\Sigma 1}, \cdots, O P_{\Sigma e}, \cdots, O P_{\Sigma E}\right)$ for each RISK $\mathrm{r}_{\mathrm{r}}$ instead of using $T H_{\Sigma e}$ and $O P_{\Sigma e}$ (as depicted in Figure 9).

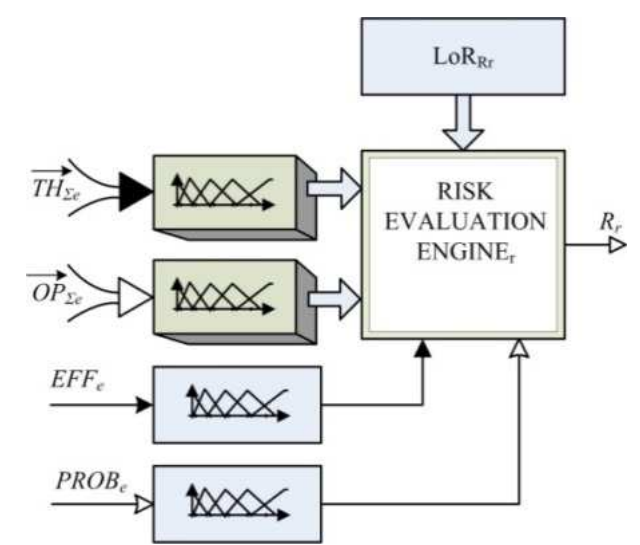

Figure 9. Networked risk-evaluation engine $r$ (RISKr) on the system's RISK_Net level.

The hesitancy, randomness, possibility, and/or probability of certain events are to be taken into account $([11,12,17,18])$, and this is symbolically expressed in Figure 9 by the input marked $P R O B_{e}$. The same applies to actions such as efforts or investments that are related to and included in the consideration. This is symbolically expressed in Figure 9 by the input marked $E F F_{e}$.

In general, each risk evaluation engine RISK $_{\mathrm{r}}$ evaluates $C=$ $2 E+2$ input variables. However, only certain variables are taken into account by expert teams when risk is being evaluated in concrete circumstances. In spite of this real fact, we begin with the full collection of input variables, only seeking to simplify the procedure of the description of the necessary list of fuzzy rules $\left(\operatorname{LoR}_{\mathrm{Rr}}\right)$ to be created by experts. An attempt to obtain a simple but sufficiently constructive IF ...THEN list of fuzzy rules dictates the need of introducing several auxiliary types of mathematical notation and operations.

First, together with the practically known and used fuzzy equality $(F E)$ in the form of $x_{e}=\left\{\alpha_{a}\right\}$ or $\left[x_{e}\right]=\left\{\alpha_{a}\right\}$, which expresses the numerical value $x_{e}$ or $\left[x_{e}\right]$ as fuzzily evaluated by the word $\left\{\alpha_{a}\right\}$ from vocabulary (3), we propose to use the fuzzy vector equality:

$$
(\mathrm{FVE}): \vec{x}=\{\vec{\alpha}\} ; \text { or }[\vec{x}]=\{\vec{\alpha}\},
$$

which means that $x_{1}=\left\{\alpha_{1}\right\}, x_{2}=\left\{\alpha_{2}\right\}, \cdots, x_{e}=\left\{\alpha_{a}\right\}$ or

$$
\left[x_{1}\right]=\left\{\alpha_{1}\right\},\left[x_{2}\right]=\left\{\alpha_{2}\right\}, \cdots,\left[x_{e}\right]=\left\{\alpha_{a}\right\} \text {. }
$$

The second newly proposed operation is described as a fuzzy AND (\&) vector equality

$$
(\mathrm{F} \& \mathrm{VE}): \& \vec{x}=\{\vec{\alpha}\}
$$

which means:

$$
x_{1}=\left\{\alpha_{1}\right\} \& x_{2}=\left\{\alpha_{2}\right\} \& \cdots \& x_{e}=\left\{\alpha_{a}\right\} .
$$

It is worth mentioning that similar operations are sometimes useful when the fuzzy OR vector equality (FORE) is needed, or in other cases.

Using the introduced mathematical notation and operations a list of fuzzy rules $\left(\mathrm{LoR}_{\mathrm{Rr}}\right)$ is created in several steps, which permit us to simplify the entire procedure:

1) Several auxiliary vectors are constructed ( $\left\{\vec{A}_{1}\right\}$, $\left.\left\{\vec{B}_{2}\right\},\left\{\vec{C}_{3}\right\},\left\{\vec{D}_{4}\right\}, \ldots,\left\{\vec{H}_{C}\right\}\right)$ using the words from vocabulary (3) and the operation of vectors concatenation CONCAT:

$$
\left\{\vec{A}_{1}\right\}=\operatorname{CONCAT}(\underbrace{\left(\left\{\alpha_{1}\right\}, \cdots,\left\{\alpha_{a}\right\}, \cdots,\left\{\alpha_{A}\right\}\right)}_{\begin{array}{c}
\text { Number of the } \\
\text { same elements } A^{0}
\end{array}}, \cdots, \underbrace{\left.\left(\alpha_{1}\right\}, \cdots,\left\{\alpha_{a}\right\}, \cdots,\left\{\alpha_{A}\right\}\right)}_{\begin{array}{c}
\text { Number of the } \\
\text { same elements } A^{0}
\end{array}})
$$

$$
\left\{\vec{B}_{2}\right\}=\operatorname{CONCAT}(\underbrace{\left(\left\{\alpha_{1}\right\}, \cdots,\left\{\alpha_{1}\right\}\right)}_{\begin{array}{c}
\text { Number of the } \\
\text { same elements } A
\end{array}}, \cdots, \underbrace{\left(\left\{\alpha_{A}\right\}, \cdots,\left\{\alpha_{A}\right\}\right)}_{\begin{array}{l}
\text { Number of the } \\
\text { same elements } A
\end{array}})
$$

Number of concatenated vectors: $A^{E-2}$ (number of groups)

$$
\left\{\vec{C}_{3}\right\}=\operatorname{CONCAT}(\underbrace{\left.\left(\alpha_{1}\right\}, \cdots,\left\{\alpha_{1}\right\}\right)}_{\begin{array}{c}
\text { Number of the } \\
\text { same elements }
\end{array} A^{2}}), \cdots, \underbrace{\left.\left(\alpha_{A}\right\}, \cdots,\left\{\alpha_{A}\right\}\right)}_{\begin{array}{l}
\text { Number of the } \\
\text { same elements } A^{2}
\end{array}})
$$

Number of concatenated vectors: $A^{E-3}$ (number of groups) 


$$
\begin{aligned}
& \left\{\vec{D}_{4}\right\}=\operatorname{CONCAT}(\underbrace{\left\{\alpha_{1}\right\}, \cdots,\left\{\alpha_{1}\right\}}_{\text {Number of the }}), \cdots, \underbrace{\left.\left.\left\{\alpha_{A}\right\}, \cdots,\left\{\alpha_{A}\right\}\right)\right)}_{\text {Number of the }} \\
& \underbrace{\text { same elements } A^{3} \quad \text { same elements } A^{3}} \\
& \text { Number of concatenated vectors: } A^{E-4} \text { (number of groups) } \\
& \left\{\vec{H}_{E}\right\}=\operatorname{CONCAT}\left((\underbrace{\left.\left\{\alpha_{1}\right\}, \cdots,\left\{\alpha_{1}\right\}\right)}_{\text {Number of the }}, \cdots, \underbrace{\left(\left\{\alpha_{A}\right\}, \cdots,\left\{\alpha_{A}\right\}\right)}_{\text {Number of the }})\right. \\
& \underbrace{\text { same elements } A^{E-1} \text { same elements } A^{E-1}} \\
& \text { Number of concatenated vectors: } A^{E-E}=A^{0}=1 \text { (number of groups) }
\end{aligned}
$$

2) For the convenience, the transposed vectors

$$
\left\{\vec{A}_{1}^{T}\right\},\left\{\vec{B}_{2}^{T}\right\},\left\{\vec{C}_{3}^{T}\right\},\left\{\vec{D}_{4}^{T}\right\}, \cdots,\left\{\vec{H}_{C}^{T}\right\}
$$

are used to construct a list of experts' sentences as a list of fuzzy antecedents (LoFA) in the shape of a LoFA matrix:

$$
\left\{\vec{A}_{1}^{T}\right\},\left\{\vec{B}_{2}^{T}\right\},\left\{\vec{C}_{3}^{T}\right\},\left\{\vec{D}_{4}^{T}\right\}, \cdots,\left\{\vec{H}_{C}^{T}\right\}
$$

with rows from 1 to $D=A^{2 E+2}(1,2,3, \cdots, d, \cdots, D)$. Row $d$

$$
\forall_{d} I F \& \operatorname{CONCAT}\left(\overrightarrow{T H}_{\Sigma}, \overrightarrow{O P}_{\Sigma}, E F F_{r}, P R O B_{r}\right)=\left\{\vec{\alpha}_{S E N T d}\right\}, T H E N R_{r d}=\left\{\alpha_{r d E X P}\right\}
$$

for every $d=1,2, \cdots, d, \cdots, D$ and $D=A^{2 E+2}$.

4) In the general case of the full-matrix LoFA, for which every input variable has and uses the same vocabulary, the length of $\mathrm{LoR}_{\mathrm{Rr}}$ is $A^{2 E+2}=\prod_{\forall e}\left|A_{e}\right|$,

$$
e=1,2, \cdots, e, \cdots, 2 E+2 \text {. }
$$

Here $\left|A_{e}\right|$ is the cardinal number of the $e$-th vocabulary and they are equal (are the same for each one)

5 ) When the length of vocabularies are different for each input variable, then the length of $L o R_{R r}$

$$
D=\prod_{\forall e}\left|A_{e}\right|=\left|A_{1}\right| \times \cdots \times\left|A_{e}\right| \times \cdots \times\left|A_{2 E+2}\right|,
$$

because "empty" rules in the matrix LoFA (20) must be omitted.

\subsection{The Leverage_Net Level}

The networking of all engines $\operatorname{AGGREG}_{1}(l=1,2, \ldots, l, \ldots, L)$ presented in Figure 6 on the LEVERAGE_Net level plays a dual role: 1) it is used to find or construct proper leverages, recommendations, or actions to improve performance in a situation in a complex environment $\mathrm{E}$, and 2) it can change the consequential parts of experts' sentences (CPS_d ) according to the selected criterion of risk optimization.
The first task on this level is achieved using data from the previous level regarding the evaluated and presented risks $R_{r}$ $(r=1,2, \ldots, r, \ldots, R)$. Different combinations of elements of the vector $\vec{R}=\left(R_{1}, \cdots, R_{r}, \cdots, R_{R}\right)$ are taken into account in the construction of one or other leverage. For this reason the number of AGGREG-engines $L \neq R$. This practice is based on requirements in real situations and the experience of an expert team.

The risks are determined, selected, and expertly evaluated verbally using an $\boldsymbol{I F} \ldots \boldsymbol{T H E N}$ type list or fuzzy rules $\left(\mathrm{LoR}_{\mathrm{Al}}\right)$, and then the reasoning must also be summarized according to the variable strategies mentioned in [13] and [14]. The list of fuzzy rules $\left(\mathrm{LoR}_{\mathrm{Al}}\right)$ for each concrete leverage $L_{l}$ (as an output of the AGGREG-engine ${ }_{l}$ ) in our case is created according to the same steps 1) - 5) presented in the subsection 3.2 above and covered by (14) - (22), with the difference that in this case here $C=R$.

For the LEVERAGE_Net level this procedure appears as follows:

1) Several auxiliary vectors are constructed ( $\left\{\vec{A}_{1}\right\}$, $\left.\left\{\vec{B}_{2}\right\},\left\{\vec{C}_{3}\right\},\left\{\vec{D}_{4}\right\}, \ldots,\left\{\vec{H}_{R}\right\}\right)$ using the words from vocabulary (3) and the operation of vectors concatenation CONCAT: 


$$
\left\{\vec{A}_{1}\right\}=\operatorname{CONCAT}(\underbrace{\left(\left\{\alpha_{1}\right\}, \cdots,\left\{\alpha_{a}\right\}, \cdots,\left\{\alpha_{A}\right\}\right.}_{\begin{array}{c}
\text { Number of the } \\
\text { same elements } A^{0}
\end{array}}, \cdots, \underbrace{(\underbrace{\left\{\alpha_{1}\right\}, \cdots,\left\{\alpha_{a}\right\}, \cdots,\left\{\alpha_{A}\right\}}_{\text {Number of concatenated vectors: }})}_{\begin{array}{c}
\text { Number of the } \\
\text { same elements } A^{0}
\end{array}})
$$

$$
\left\{\vec{B}_{2}\right\}=\operatorname{CONCAT}(\underbrace{\left.\left\{\alpha_{1}\right\}, \cdots,\left\{\alpha_{1}\right\}\right)}_{\begin{array}{c}
\text { Number of the } \\
\text { same elements } A
\end{array}}, \cdots, \underbrace{\left(\left\{\alpha_{A}\right\}, \cdots,\left\{\alpha_{A}\right\}\right)}_{\begin{array}{c}
\text { Number of the } \\
\text { same elements } A
\end{array}})
$$

Number of concatenated vectors: $A^{R-2}$ (number of groups)

$$
\left\{\vec{C}_{3}\right\}=\operatorname{CONCAT}(\underbrace{\left.\left(\alpha_{1}\right\}, \cdots,\left\{\alpha_{1}\right\}\right), \cdots, \underbrace{\left.\left.\left(\alpha_{A}\right\}, \cdots,\left\{\alpha_{A}\right\}\right)\right)}_{\text {Number of the }}}_{\begin{array}{c}
\text { Number of the } \\
\text { same elements } A^{2}
\end{array}}
$$

Number of concatenated vectors: $A^{R-3}$ (number of groups)

$$
\left\{\vec{D}_{4}\right\}=\operatorname{CONCAT}(\underbrace{(\underbrace{}_{\text {Number of the }} \begin{array}{l}
\text { same elements } A^{3} \\
\text { same }
\end{array}}_{\begin{array}{c}
\text { Number of the } \\
\text { same elements } A^{3}
\end{array}}
$$

Number of concatenated vectors: $A^{R-4}$ (number of groups)

$$
\begin{aligned}
& \left\{\vec{H}_{R}\right\}=\operatorname{CONCAT}(\underbrace{\text { Number of concatenated vectors: } A^{R-R}=A^{0}=1 \text { (number of groups) }}_{\left.\begin{array}{l}
\text { Number of the } \\
\text { same elements } A^{R-1}\left\{\alpha_{1}\right\}, \cdots,\left\{\alpha_{1}\right\}
\end{array}\right), \cdots, \underbrace{\left.\left.\left(\alpha_{A}\right\}, \cdots,\left\{\alpha_{A}\right\}\right)\right)}_{\begin{array}{l}
\text { Number of the } \\
\text { same elements } A^{R}
\end{array}}}
\end{aligned}
$$

2) For convenience, the transposed vectors here

$$
\left\{\vec{A}_{1}^{T}\right\},\left\{\vec{B}_{2}^{T}\right\},\left\{\vec{C}_{3}^{T}\right\},\left\{\vec{D}_{4}^{T}\right\}, \cdots,\left\{\vec{H}_{R}^{T}\right\}
$$

are used to construct a list of experts' sentences as a LoFA matrix:

$$
\left\{\vec{A}_{1}^{T}\right\},\left\{\vec{B}_{2}^{T}\right\},\left\{\vec{C}_{3}^{T}\right\},\left\{\vec{D}_{4}^{T}\right\}, \cdots,\left\{\vec{H}_{R}^{T}\right\}
$$

with a number of rows from $d=1,2, \ldots, d, \ldots D$ and $D=A^{R}$. Row $d$

$$
\{\vec{d}\}=\left(\left\{\vec{A}_{1 d}^{T}\right\},\left\{\vec{B}_{2 d}^{T}\right\},\left\{\vec{C}_{3 d}^{T}\right\},\left\{\vec{D}_{4 d}^{T}\right\}, \cdots,\left\{\vec{H}_{R d}^{T}\right\}\right)
$$

here is described as an antecedent part of an expert's fuzzy verbal sentences (APS_d), which corresponds to the consequential part of the same sentence as an expert's decision $\left(C P S \_d\right)$ (or suggestion) $\left\{\alpha_{\text {ldEXP }}\right\}$.

3) Thus, the fuzzy rules of the list LoRLl exhibit fuzzy AND (\&) vector (F\&VE) qualities, as follows:

$$
\forall_{d} I F \&(\vec{R})=\left\{\vec{\alpha}_{S E N T d}\right\}, T H E N L_{l d}=\left\{\alpha_{l d E X P}\right\}
$$

for every $d=1,2, \cdots, d, \cdots, D$ and $D=A^{R}$.

4) In the general case of a full-matrix LoFA, where every input variable has and uses the same vocabulary, the length of $\mathrm{LoR}_{\mathrm{Ll}}$ is $A^{R}=\prod_{\forall \mathrm{r}}\left|A_{r}\right|, r=1,2, \cdots, r, \cdots, R$. Here $\left|A_{r}\right|$ is the cardinal number of the $r$-th vocabulary, and they are equal (are the same for each vocabulary).

5) When the lengths of the vocabularies are different for the different input variables, then the length of $\mathrm{LoR}_{\mathrm{Ll}}$ is as follows:

$$
D=\prod_{\forall r}\left|A_{r}\right|=\left|A_{1}\right| \times \cdots \times\left|A_{r}\right| \times \cdots \times\left|A_{R}\right|
$$

because the empty rules in the matrix LoFA (20) must be omitted.

The second task for this level is achieved using an additional block for risk optimization on the same LEVERAGE_Net level as depicted in Figure 10. 


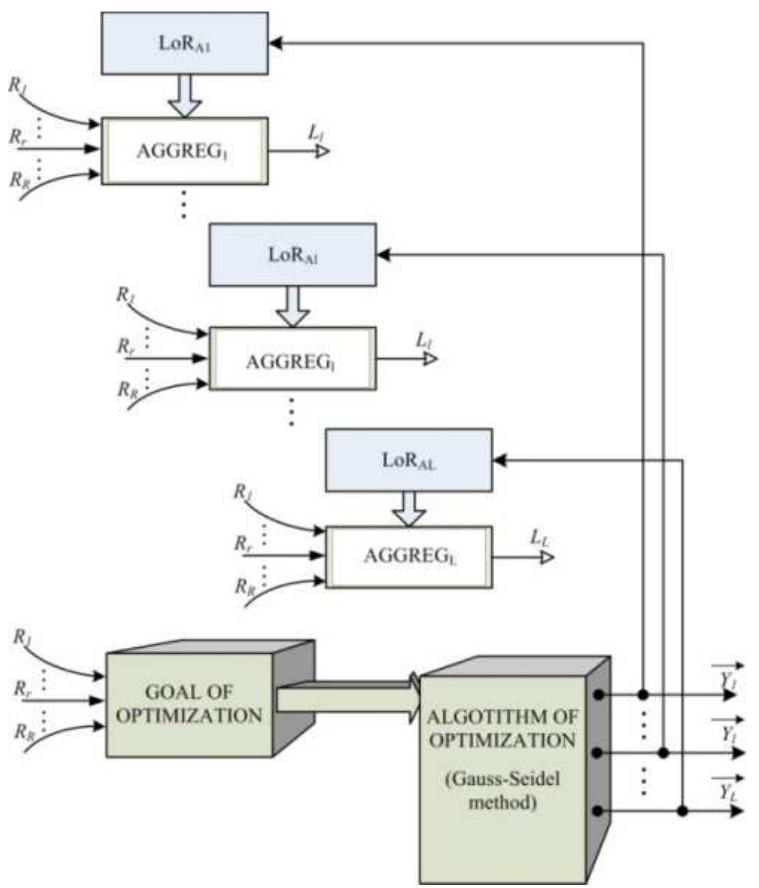

Figure 10. Additional block for risk optimization.

Let us call criterion $R_{\Sigma}$ and use the well-known GaussSeidel algorithm (as it appears in, for example, [22]) to minimize it (as it is shown symbolically in Figure 11).

In this case, $R_{\Sigma}$ is a complicated function of words $\{\vec{\alpha}\}(3)$, used to describe experts' opinions, and vectors $\vec{Y}_{l}(l=1, \ldots$, $l, \ldots, L)$ represent the CPS_d changes to be made in the corresponding lists of rules $\operatorname{LoR}_{\mathrm{Al}}$ :

$$
R_{\Sigma}=\left(\{\vec{\alpha}\}, \vec{Y}_{1}, \ldots, \vec{Y}_{l}, \ldots, \vec{Y}_{L}\right) ;
$$

Each vector $\vec{Y}_{l}$ has $A^{R}$ components, and these components correspond to the consequential parts of the sentences $\left(C P S \_d\right)$ $\left\{\alpha_{\text {ldEXP }}\right\}$ of experts.

The space where possible optimal solution must be found can be described through a detailed presentation of a system of vectors $\vec{Y}_{l}(l=1, \ldots, l, \ldots, L)$ :

$$
\left\{\begin{array}{l}
\vec{Y}_{1}=\left(\left\{y_{11}\right\}, \cdots,\left\{y_{1 l}\right\}, \cdots\left\{y_{1 A^{R}}\right\}\right) \\
\vec{Y}_{l}=\left(\left\{y_{l 1}\right\}, \cdots,\left\{y_{l l}\right\}, \cdots\left\{y_{l A^{R}}\right\}\right) \\
\vec{Y}_{l}=\left(\left\{y_{L 1}\right\}, \cdots,\left\{y_{L l}\right\}, \cdots\left\{y_{L A^{R}}\right\}\right)
\end{array}\right.
$$

The values on the all axes (for example, on the $\mathrm{y}_{l 1}$ and/or $\left.\mathrm{y}_{l A}{ }^{R}\right)$ are expressed in verbal form, using the same vocabulary vector $\{\vec{\alpha}\}=\left(\left\{\alpha_{1}\right\}, \cdots,\left\{\alpha_{a}\right\}, \cdots,\left\{\alpha_{A}\right\}\right)$, as was presented in (3).

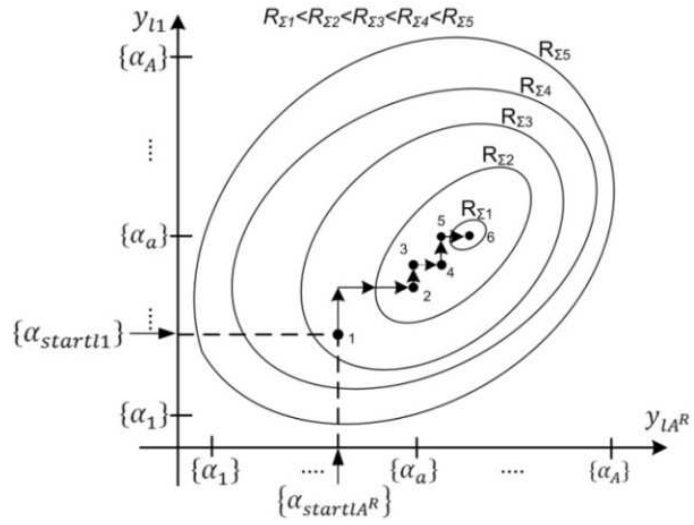

Figure 11. Illustration of performance of the Gauss-Seidel algorithm.

\section{Systems Implementation}

The functional organization of all subsystems described in section 3, appears in the structure of the integral conceptual system, presented in Figure 12.

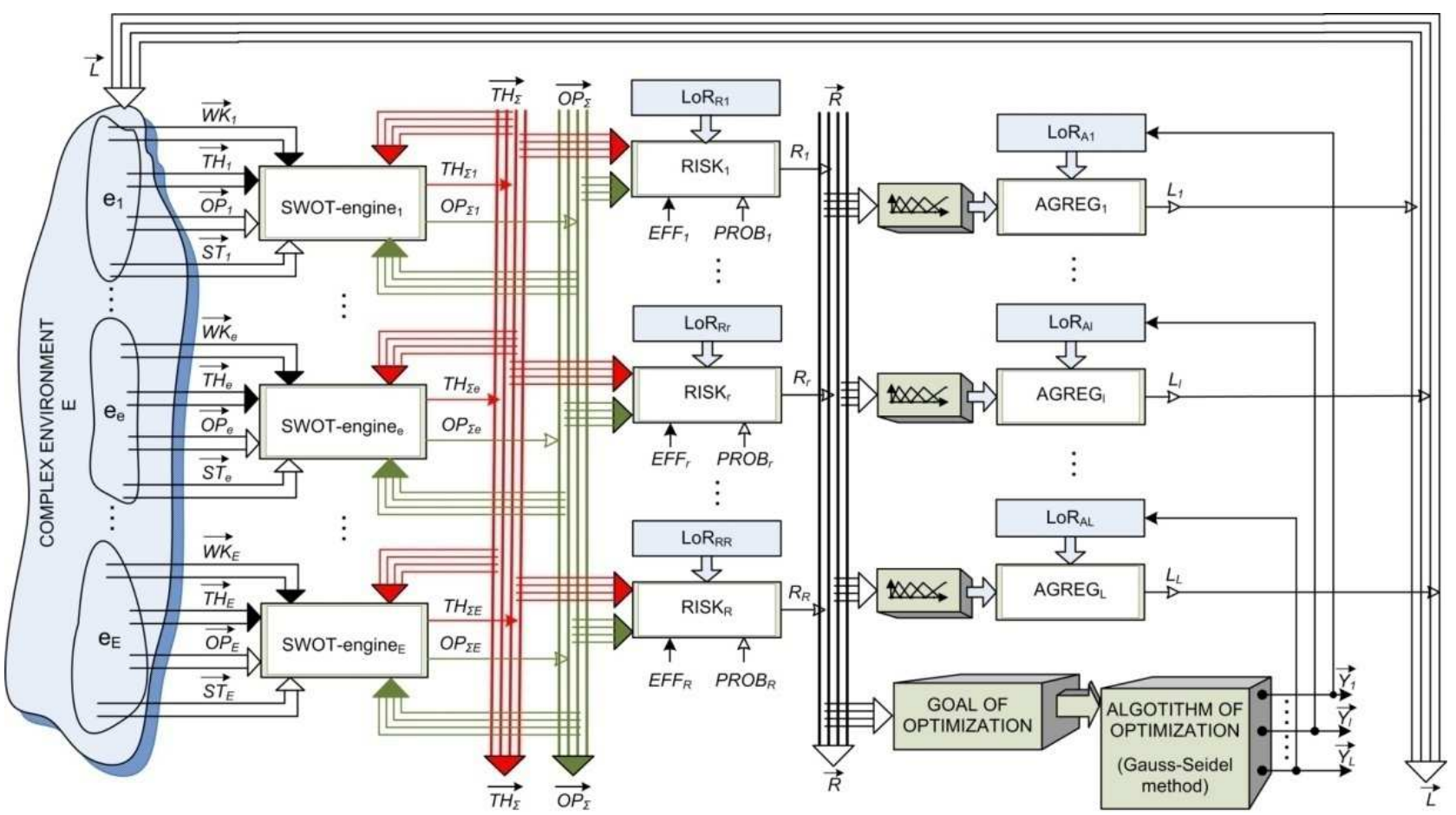

Figure 12. Integrated conceptual structure of the system developed using dynamic SWOT analysis network for fuzzy control of risk in complex environments. 
The implementation of the concept depends on three practical considerations.

First, software tools for the operations and procedures prescribed by the concept must be available. Fortunately, a set of suitable tools exists. The main kernel tool for verbal SWOT analysis, enriched by methodology of CWW $(\mathrm{SWOT}+\mathrm{CWW})$, was proposed and successfully developed in the Center of Real Time Computing Systems at Kaunas University of Technology (KTU) ([8]). Many other tools are described in [9]. Other important fuzzy operations are described in [21 - 23] together with the software used for their interactions.

Second, the more or less technical side of the interaction and interface between the complex environments and the risk control system must be assessed. Among other extremely important characteristics, knowledge of the spatial and temporal parameters of the environment under investigation and its dynamical behavior must be reviewed. The development of the concept presented in this paper does not provide any recommendation on the information inputs necessary for SWOT engines on the RISK_Net level. The same can also be said on the system's outputs in the form of different leverages $\vec{Y}_{l}(l=1, \ldots, l, \ldots, L)$ (recommendations or actions to improve performance in a complex environment). From one point of view, this is a drawback because in each concrete case, thorough studies are needed of the activities of subsystems and environmental situations, including the types, forms, and technical characteristics and features of possible inputs and appropriate outputs. On the other hand, this guarantees the universality of the concept that we advocate in this paper.

Third, the existence, availability, and presentation of rich and reliable experience and archived data should be taken into account in the context of necessary lists of rules $\operatorname{LoR}_{\mathrm{Rr}}(r=1$, $2, \ldots, r, \ldots, R)$ and $\operatorname{LoR}_{\mathrm{Al}}(l=1,2, \ldots, l, \ldots, L)$ are to be constructed. Currently, as when SWOT evaluation must be performed, the human factor plays a significant role, and high requirements for the qualifications for expert teams would be welcome.

\section{Experimental Modeling}

Only a small part of a risk-control system covering three interacting projects in a complex environment is illustrated in this paper. Here, a new approach to the FCM extension is emphasized on the SWOT engines' networking level. This was delivered in Section 3 under the name of fuzzy SWOT nodes that together form an FSM.

Here, we present short description of the three interacting projects. The first one is the construction of a hotel complex in a recreational area on the Baltic Sea coast in Palanga, Lithuania. This project is entitled HOTEL. A simplified description of the SWOT entities under evaluation in the HOTEL project is given in Table 2.
Table 2. Construction of hotel complex in recreational area.

\begin{tabular}{lll}
\hline SWOT entity & Description & Abbreviation \\
\hline $\mathrm{ST}_{11}$ & Significant financing & $\{\mathrm{SF}\}$ \\
$\mathrm{ST}_{12}$ & High-quality personnel & $\{\mathrm{Q} o \mathrm{\}}\}$ \\
$\mathrm{WK}_{11}$ & Lack of infrastructure & $\{\mathrm{LoI}\}$ \\
$\mathrm{WK}_{12}$ & High storm levels & $\{\mathrm{LoS}\}$ \\
$\mathrm{WK}_{13}$ & Increasing protests of local community & $\{\mathrm{PoC}\}$ \\
$\mathrm{OP}_{11}$ & Erection of modern hotel complex & $\{\mathrm{HC}\}$ \\
$\mathrm{OP}_{12}$ & Developed modern infrastructure & $\{M I\}$ \\
$\mathrm{OP}_{13}$ & High prospective revenue & $\{H R\}$ \\
$\mathrm{TH}_{11}$ & Increased erosion of dunes & $\{E o D\}$ \\
$\mathrm{TH}_{12}$ & Increased environmental pollution & $\{P o E\}$ \\
\hline
\end{tabular}

The second project, entitled GAS STATION, is intended to construct and open a new gasoline station in the same city, Palanga. A description of the SWOT entities of that project is given in Table 3 .

Table 3. Constructing and opening new gasoline station.

\begin{tabular}{lll}
\hline SWOT entity & Description & Abbreviation \\
\hline ST21 & Corporate experience & $\{E X\}$ \\
ST22 & Sufficient financial support & $\{F S\}$ \\
WK21 & Lack of personnel & $\{L o P\}$ \\
WK22 & Time shortages & $\{S o T\}$ \\
OP21 & High expected revenue & $\{R V\}$ \\
OP22 & Improved infrastructure & $\{I S\}$ \\
OP23 & Convenience of service & $\{C o S\}$ \\
TH21 & Additional pollution of the city & $\{P L\}$ \\
TH22 & Unnecessary competition & $\{U C\}$ \\
TH23 & Additional obstacles for pedestrians & $\{O f P\}$ \\
\hline
\end{tabular}

The third project has the task of facilitating the two projects mentioned above and discovering new additional possibilities for the development of the whole recreational region under consideration. This project is called LOBBY, and its SWOT description is given in Table 4.

The preliminary results of experimental modeling achieved by using created prototypical SWOT-enhanced CWW tools expanded the evaluate connections among projects for the evaluation and vitality of the idea are presented. Verbal descriptions are given for all three projects and are presented in Tables 5-7.

Table 4. Organizing the governmental lobbying.

\begin{tabular}{lll}
\hline SWOT entity & Description & Abbreviation \\
\hline ST31 & High-quality personnel & $\{Q o P\}$ \\
ST32 & Effective communication network & $\{C N\}$ \\
WK31 & Lack of personnel & $\{L o P\}$ \\
WK32 & Time shortages & $\{S o T\}$ \\
OP31 & Governmental support & $\{G S\}$ \\
OP32 & Foreign investment & $\{F I\}$ \\
OP33 & Legal flexibility & $\{F o L\}$ \\
TH31 & Negative press reaction & $\{N P\}$ \\
TH32 & Loss of reliability & $\{L o R\}$ \\
\hline
\end{tabular}

Table 5. SWOT $+C W W$ evaluation matrix for the HOTEL project

\begin{tabular}{llllllll}
\hline & C & p & SF & QoP & LoI & LoS & PoC \\
\hline HC & VL & VL & L & L & M & L & L \\
MI & VL & VL & L & VL & L & L & M \\
HR & VL & VL & L & L & M & M & L \\
EoD & VL & VL & VS & Z & S & L & M \\
PoE & VL & VL & M & Z & VS & M & L \\
\hline
\end{tabular}


Table 6. SWOT $+C W W$ evaluation matrix for the GAS STATION project

\begin{tabular}{lllllll}
\hline & C & p & EX & FS & LoP & SoT \\
\hline RV & VL & VL & L & M & VL & L \\
IS & VL & VL & L & L & VL & L \\
CoS & VL & VL & L & L & L & VS \\
PL & VL & VL & S & S & Z & M \\
UC & VL & VL & L & L & L & Z \\
OfP & VL & VL & M & M & L & L \\
\hline
\end{tabular}

Table 7. SWOT $+C W W$ evaluation matrix for the LOBBYING project

\begin{tabular}{lllllll}
\hline & C & p & QoP & CN & LoP & SoT \\
\hline GS & VL & VL & L & L & M & L \\
FI & VL & VL & L & L & L & L \\
FoL & VL & VL & L & L & M & M \\
NP & VL & VL & L & L & S & L \\
LoR & VL & VL & M & L & L & M \\
\hline
\end{tabular}

The role of the SWOT engines in networking and constructing the FSMs begins with the following considerations from the expert team 1) it is agreed the that summarized opportunity $\left(O P_{\Sigma I}\right)$ of HOTEL has a positive influence on the success of GAS STATION opportunity; 2 ) the summarized threat $\left(T H_{\Sigma l}\right)$ of HOTEL has a negative influence on LOBBY's success and increases its summarized threat; 3 ) the summarized opportunity of LOBBY $\left(O P_{\Sigma 3}\right)$ has a positive influence on HOTEL's its summarized opportunity and a negative influence on GAS STATION's success (increases its summarized threat); 4) it is agreed that the summarized threat of LOBBY $\left(T H_{\Sigma 3}\right)$ positively influences the success of GAS STATION (increases its $O P_{\Sigma 2}$ ). These interconnections among the three projects are depicted in Figure 13 for illustrative modeling.

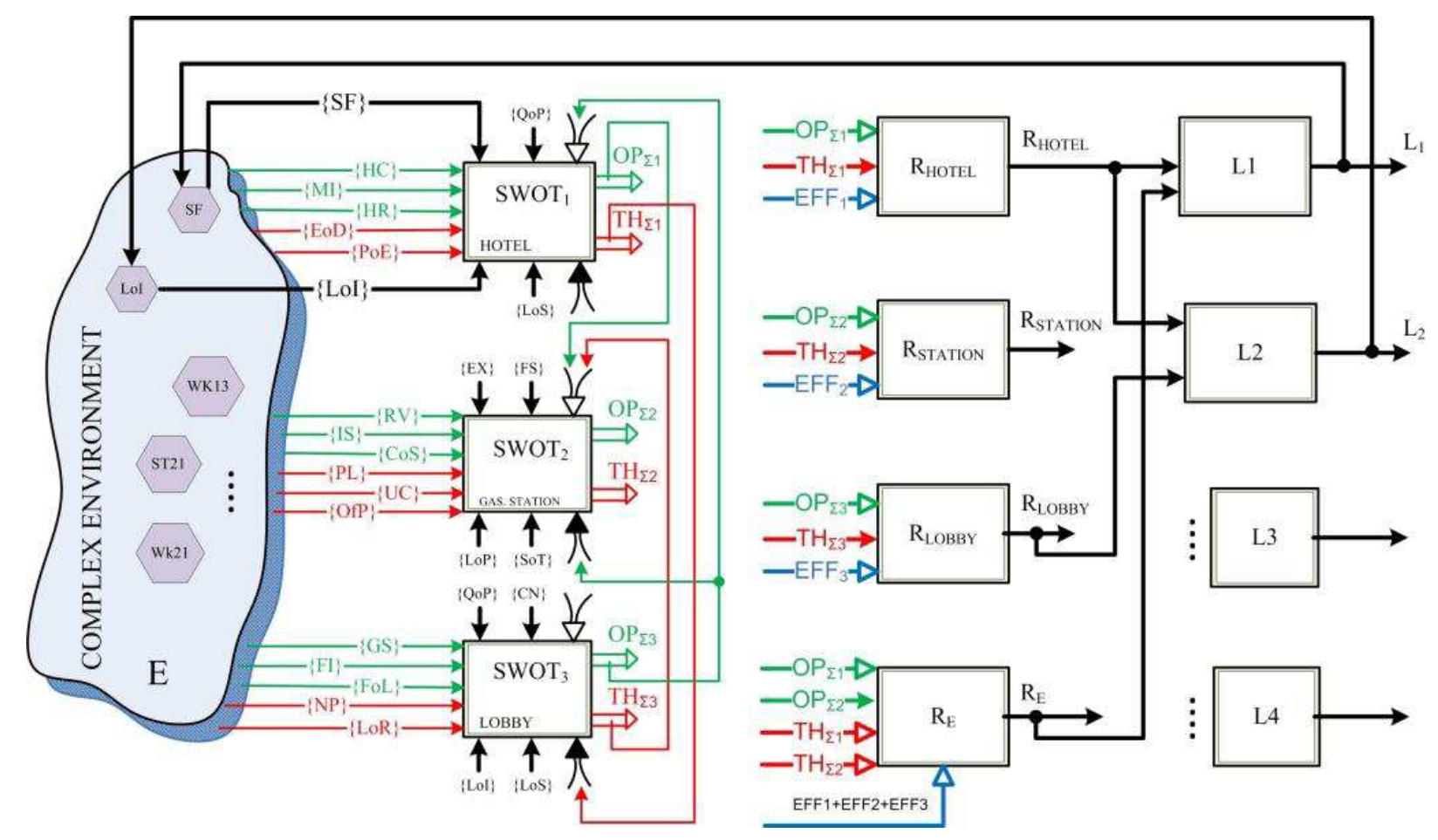

Figure 13. Fragment of model of the complex environment of the three interacting projects.

The connections among the three interacting projects under investigation are shown in Figure 13 and are implemented using the interface described in [8] for SWOT analysis enriched with CWW elements.

In this case, a user can select a certain project and make necessary connections influencing the components of another project's component (opportunity or threat), taking into account the polarity of influence (positive or negative) and its certainty. This certainty can be expressed as absolute, digital, or verbal, as shown in Figure 14. Figures 15-17 exhibit the verbal interface for the expert or user and the $\mathrm{SWOT}+\mathrm{CWW}$ tool for the interacting projects, following Figure 13.

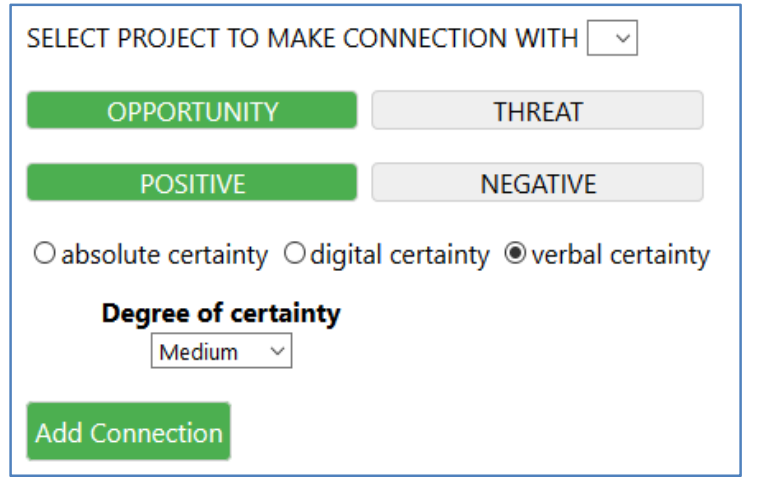

Figure 14. Verbal interface for the user or expert and the $S W O T+C W W$ tool for projects connections. 


\begin{tabular}{|c|c|c|c|c|c|}
\hline \multirow{2}{*}{\multicolumn{6}{|c|}{$\begin{array}{l}\text { CONNECTIONS FROM THIS PROJECT: } \\
\begin{array}{|l|l|}\text { No. Component } & \text { Polarity } \\
\text { SWOT+CWW project title }\end{array}\end{array}$}} \\
\hline & & & & & \\
\hline 1 & $\mathrm{OP}$ & + & Constructing and opening new gasoline station & GAS STATION & Delete \\
\hline 2 & $\mathrm{TH}$ & + & Organizing the governmental lobbying & LOBBY & Delete \\
\hline
\end{tabular}

CONNECTIONS TO THIS PROJECT:

\begin{tabular}{|c|l|l|c|c|c|}
\hline No. & Component & Polarity & SWOT+CWW project title & Acronym & \\
\hline 1 & $\mathrm{OP}$ & + & Organizing the governmental lobbying & LOBBY & Delete \\
\hline
\end{tabular}

Figure 15. Connections for the HOTEL project

\section{CONNECTIONS FROM THIS PROJECT: \\ No. Component Polarity SWOT +CWW project title Acronym}

CONNECTIONS TO THIS PROJECT:

\begin{tabular}{|c|l|l|l|c|c|}
\hline No. & Component & Polarity & \multicolumn{1}{|c|}{ SWOT+CWW project title } & Acronym & \multicolumn{1}{|c|}{} \\
\hline 1 & TH & - & Organizing the governmental lobbying & LOBBY & Delete \\
\hline 2 & OP & + & Erection of hotel complex in the area of recreation & HOTEL & Delete \\
\hline 3 & OP & - & Organizing the governmental lobbying & LOBBY & Delete \\
\hline
\end{tabular}

Figure 16. Connections for the GAS STATION project

\begin{tabular}{|c|c|c|c|c|c|c|}
\hline \multicolumn{6}{|c|}{ CONNECTIONS FROM THIS PROJECT: } & \\
\hline \multicolumn{3}{|c|}{\begin{tabular}{|l|l|l|} 
No. & Component & Polarity \\
\end{tabular}} & SWOT +CWW project title & \multicolumn{2}{|c|}{ Acronym } & \\
\hline 1 & OP & + & Erection of hotel complex in the area of recreation & \multicolumn{2}{|c|}{ HOTEL } & Delete \\
\hline 2 & $\mathrm{TH}$ & - & Constructing and opening new gasoline station & \multicolumn{2}{|c|}{ GAS STATION } & Delete \\
\hline 3 & OP & - & Constructing and opening new gasoline station & \multicolumn{2}{|c|}{ GAS STATION } & Delete \\
\hline \multicolumn{7}{|c|}{ CONNECTIONS TO THIS PROJECT: } \\
\hline \multirow{2}{*}{\begin{tabular}{|c|} 
No. \\
1
\end{tabular}} & Component & Polarity & SWOT+CWW project title & \multicolumn{3}{|l|}{ Acronym } \\
\hline & TH & + & Erection of hotel complex in the area of recreation & HOTEL & Delete & \\
\hline
\end{tabular}

Figure 17. Connections for the LOBBYING project

To better represent the interacting projects described, the starting point for connections among the projects is exhibited in Figure 18. Initial opportunities and threats relating to pessimistic, optimistic, and moderate approaches of expert teams for corresponding projects are shown as well.

The results of the iterative interactions displayed for user's convenience on the screen of the SWOT $+\mathrm{CWW}$ tool for five consequent iterations are indicated in Figure 19.
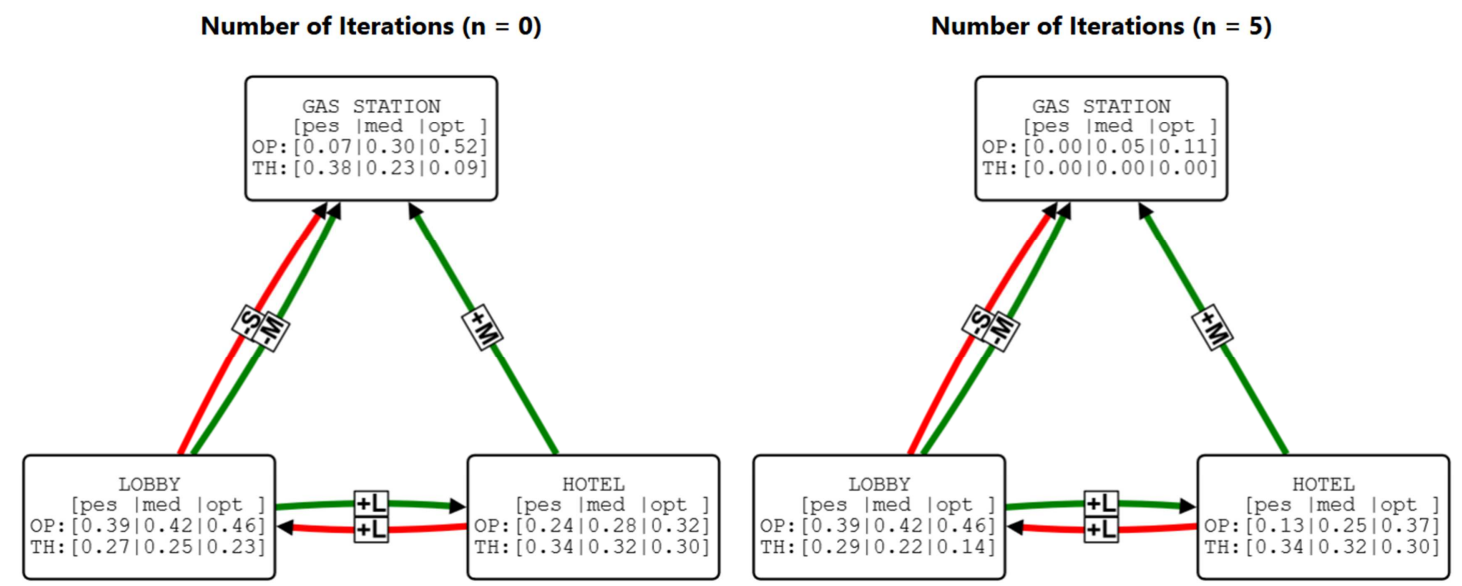

Figure 18. Interconnections among projects using data at the starting point $(n=0)$ and after five iterations $(n=5)$. 


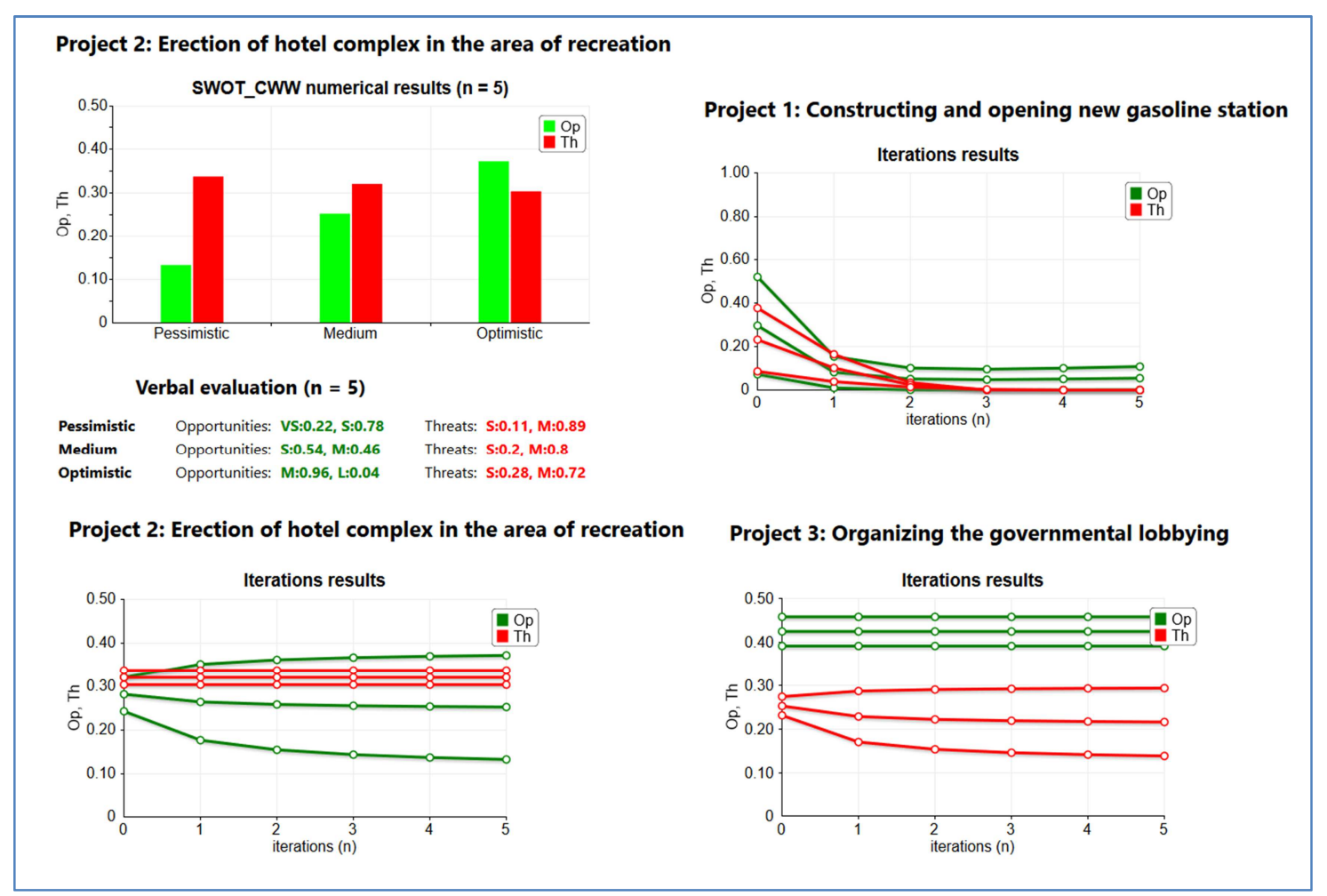

Figure 19. User's screen image from the SWOT $+C W W$ tool.

Even a preliminary glance at these results allows us to draw several conclusions concerning the attractiveness and possible reliability of the interaction of these projects at this stage of investigation and reasoning. For instance, it is readily apparent that only LOBBY is attractive with given data, while GAS STATION is dubious and the prospects for HOTEL are poor indeed.

This if the team of experts and/or possible users of the complex environment wish to exploit the complex of these three interacting and mutually supporting projects, the next steps of the concept proposed in this paper should be activated: risk evaluation, leverage investigation (leverages, recommendations, and actions to be proposed as feedback to the complex environment), and establishment of tools for risk optimization. We consider that the results of these actions are beyond the target of this paper. On the other hand, the answers to the questions listed above require additional study in the modeling of virtual reality of the whole complex environment itself, and sophisticated interface tools must be used with real environments to use the concept in real scale and with real time control.

\section{Concluding Remarks}

In this paper, we have proposed an entirely novel concept that combines three levels of tools devoted for dynamic SWOT analysis and fuzzy control of risk in complex environments into one organic, closed-loop feedback system. This concept can be used to perform modeling in a virtual environment as well as in real time complex control systems, in cases of several interacting projects, ideas, or processes under investigation or control. The concept covers: 1) the evaluation (through dynamic SWOT analysis) of the positive and negative features of the interactive situation under investigation, 2) the determination of the level of fuzzy risk appearing in this situation (through RISK evaluation), and the 3) leverages, recommendations, or actions to be proposed and adopted (through LEVERAGE aggregation) enabling the improvement of performance in the situation with all interacting projects or processes.

The concept we have developed and used incorporates new fundamental approaches and definitions concerning the dynamic SWOT analysis, a practical, convenient, and constructive definition of RISK, and a fuzzy engineering approach based on LEVERAGE aggregation with a risk-optimization system based on the automatic changes of corresponding consequents in lists of fuzzy rules.

For the first time we have proposed and used dynamic SWOT analysis modules/tools enhanced with elements of CWW permitting to use verbal evaluations of strengths, weaknesses, opportunities and threats as well as numerical ones on the level of Fuzzy 2 systems ([14]).

For the first time, we have proposed, and used interacting SWOT modules connected into the dynamic fuzzy SWOT analysis network, here called as fuzzy SWOT maps (FSM), and corresponding to the interacting projects, ideas or processes under investigation or/and control.

The whole functional organization of the closed loop feedback system for the fuzzy control of risk in complex environments is delivered.

The results of conceptual experimental modeling of a network of interacting elements of FSMs that correspond to 
the three interacting projects under investigation confirm the vitality of the approach and concept presented in the paper.

\section{References}

[1] S. Emmott and others. Towards 2020 Science, Microsoft Corporation, 2006. Accessed November 22, 2006. (http://research.microsoft.com/towards2020science/downloads /T2020S_ReportA4.pdf).

[2] R. Jasinevicius, Why today's systems theory can't cope with global environmental or marine systems catastrophes and crises? in: Proceedings of Baltic International Symposium (BALTIC), 2010 IEEE/OES US/EU, August 2010 Riga, Latvia, pp. 24-27, 2010.

[3] R. Jasinevicius, V. Petrauskas, On fundamentals of global systems control science (GSCS), in: A. Sanayei, I. Zelinka, O. Rössler (Eds.) ISCS 2013: Interdisciplinary Symposium on Complex Systems. Emergence, Complexity and Computation, vol. 8, pp. 77-87, Springer, Berlin, Heidelberg, 2014.

[4] E. Gurel, M. Tat, SWOT analysis: A theoretical review. The Journal of International Social Research, vol. 10, no. 51, pp. 994-1006, 2017.

[5] R. Jasinevičius, V. Petrauskas, Dynamic SWOT analysis as a tool for environmentalists. Environmental Research, Engineering and Management. vol. 1, no. 43, pp. 14-20, 2008.

[6] R. Jasinevičius, V. Petrauskas, Dynamic SWOT analysis as a tool for system experts. Engineering Economics, vol. 5 no. 50, pp. 33-35, 2006.

[7] T. Aven, Risk assessment and risk management: Review of recent advances on their foundation, European Journal of Operational Research, vol. 253, pp. 1-13, 2016.

[8] V. Petrauskas, R. Jasinevicius, E. Kazanavicius, Z. Meskauskas, CWW elements to enrich SWOT analysis, Journal of Intelligent \& Fuzzy Systems, vol. 34, no. 1, pp. 307-320, 2018

[9] A. Balzekiene, E. Gaule, R. Jasinevicius, E. Kazanavicius, V. Petrauskas, Risk evaluation: the paradigm and tools, in: Dregvaite G., Damasevicius R. (eds) Information and Software
Technologies. ICIST 2015. Communications in Computer and Information Science, vol. 538, Springer, Cham, pp. 330-342, 2015.

[10] A. Šotic, R. Rajic, The review of the definition of risk, Online Journal of Applied Knowledge Management, vol. 3, no. 3, pp. 17-26, 2015.

[11] K. T. Atanassov, On intuitionistic fuzzy sets theory. New York, NY: Springer, 2012.

[12] L.-H. Chen, C.-C. Tu, Dual bipolar measures of Atanassov' intuitionistic fuzzy sets, IEEE Transactions on Fuzzy Systems, vol. 22, No. 4, pp. 966-982, 2014.

[13] B. Kosko, Fuzzy engineering. Prentice-Hall, N. J., 1997.

[14] A. Konar, Computational intelligence: Principles, techniques and applications, Berlin: Springer, 2005.

[15] R. Jasinevičius, V. Petrauskas, Sprendimų pagrindimo kompiuterizavimas (Computerization of decision making), Kaunas, Lithuania: Technologija, 2011.

[16] H. Liao, X. Mi, Z. Xu, J. Xu, F. Herrera, Intuitionistic fuzzy analytic network process, IEEE Transactions on Fuzzy Systems, vol. 26, no. 5, pp. 2578-2590, 2018.

[17] E. Herrera-Viedma, F. J. Cabrerizo, J. Kacprzyk, and W. Pedrycz, A review of soft consensus models in a fuzzy environment, Information Fusion, vol. 17, pp. 4-13, 2014.

[18] Z. Xu, Hesitant fuzzy sets theory, Studies in Fuzziness and Soft Computing. Springer, 2014.

[19] R. Axelrod, Structure of decision: The cognitive maps of political elites, Princeton, NJ: Princeton University Press, 1976.

[20] B. Kosko, Fuzzy cognitive maps, International Journal of Man-Machine Studies, Vol. 24, pp. 65-75, 1986.

[21] R. Jasinevicius, V. Petrauskas, Fuzzy expert maps: The new approach, in: Proceedings of 2008 IEEE International Conference on Fuzzy Systems (IEEE World Congress on Computational Intelligence), Hong Kong, China, pp. 15111517,2008 